\title{
Global Market Analysis for Welding Power Source and Welding Robot (I)
}

\author{
Seungjae Lee*,**, Jason Cheon* and Cheolhee Kim*,***, ${ }^{*}$ \\ *Research Institute of Advanced Manufacturing Technology, Korea Institute of Industrial Technology, \\ Incheon, 21999, Korea \\ **Department of Politics and International Relations, Incheon National University, Incheon, 22012, Korea \\ ***Department of Mechanical \& Materials Engineering, Portland State University, Portland, OR 97201, USA \\ †Corresponding author : chkim@kitech.re.kr \\ (Received March 10, 2020 ; Revised March 19, 2020 ; Accepted April 2, 2020)
}

\begin{abstract}
Welding power source and welding robot are the most important components of welding automation systems. In this paper, we summarized the sales and market revenues of welding power source and welding robot using the market analysis reports from 2007 to 2017. The analysis was conducted for arc welding and resistance welding, respectively. The power source market of 2017 returned to that of 2007, and the welding robot market of 2017 approximately doubled that of 2007 . These market trends are found to be closely related to the major application industries such as the heavy industry and the automotive industry.
\end{abstract}

Key Words : Market analysis, Welding power source, Welding robot, Arc welding, Resistance spot welding

\section{Introduction}

The authors have been introducing the trends of the Korean welding and joining industry ${ }^{1-4)}$ and the global welding material industry, ${ }^{5,6)}$ through the Journal of Welding and Joining. This article will introduce and summarize the status of the welding power source and robot market. According to the Welding and Joining Handbook from Korean Welding and Joining Society, welding automation systems utilizing robots consist of robot arms, controllers, welding power sources, transport devices for welded specimens, robot movement devices, sensors, safety devices, and fixing devices for welded specimens ${ }^{7)}$. Their most important components are the welding robots (robot arms and controllers) and welding power source, which are commercialized by specialized companies and applied in the industry. This article introduces the market status of the welding robot and welding power source using data from 2007 to 2017 in "Welding Market Annual Research \& Trend" (MART) published by Shinbo ${ }^{8}$. This article classifies welding robots and welding power sources into arc welding and resistance welding, and summarizes the global market status and market status of major consuming countries.

\section{Status of the Global Welding Power Source Market}

In the global welding power source market, both the arc welding and resistance welding power sources

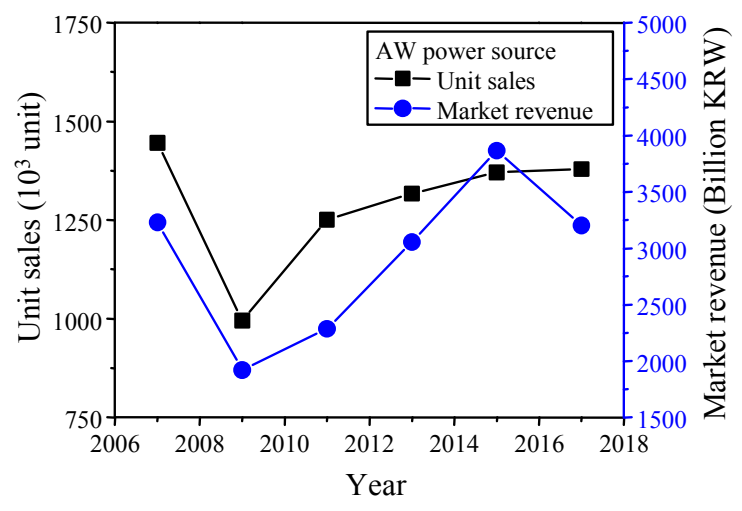

Fig. 1 Global market trends for arc welding power source 


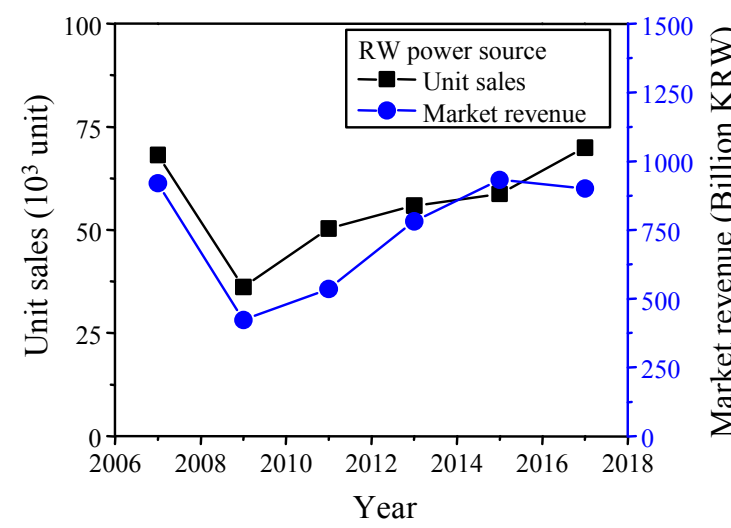

Fig. 2 Global market trends for resistance welding power source

recorded the lows in the 2008 global economic crisis and are now recovering to their pre-crisis levels. (Figs. $1 \& 2$ ) Over the survey period, the global arc welding power source market recorded average sales of 1.3 million units and 2.5 billion dollars, while the resistance welding power source market recorded average sales of 55,000 units and 620 million dollars. However, considering the recovery trends since 2008, the data from 2007 and 2017 are better suited for the current status than the average one. As arc welding power sources include low-cost shield metal arc welding (SMAW) power sources, its market has 23 times more units and 4 times more sales than the resistance welding market.

The data for arc welding power source market by country show that the markets have exited the recession of the 2008 global economic crisis. (Fig. 3) In the Korean market, the decline in arc welding power source sales due to the 2008 global economic crisis was relatively small compared to other countries. Given that the primary application field for arc welding power sources is heavy industry, heavy industry in Korea likely did not have severe decline in the expenditure on welding power source at the time.

According to the unit price of arc welding power sources by country using the country-specific unit sales and revenue data in Fig. 3 (a) and 3 (b), the unit price of arc welding power sources in Korea is about half of that in the United States or Japan, and the unit price of arc welding power sources in China is just over a third of that in the United States or Japan. (Table 1) Regarding arc welding power sources, given that the price of SMAW power source for manual welding is approximately $1 / 10$ that of GMAW power source for semi-automatic or automatic welding, the unit price of arc welding power sources is highly related to the automation rate in application industries. Meanwhile, the manual welding application has a considerably high portion in China.

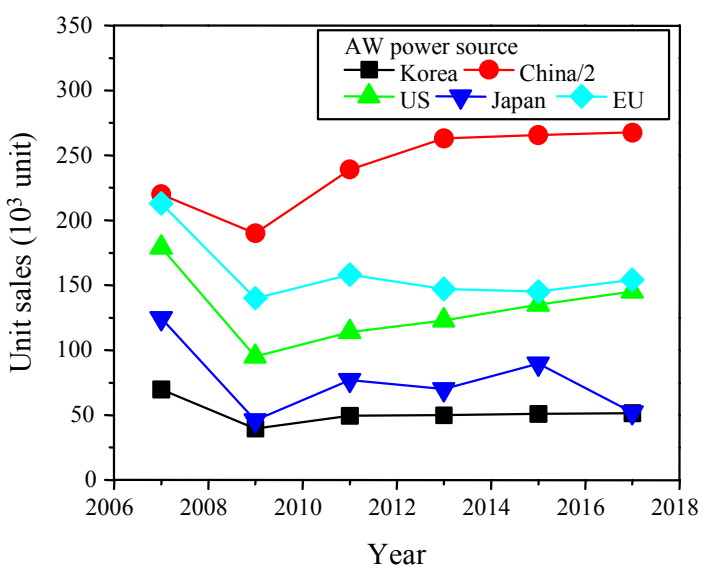

(a)

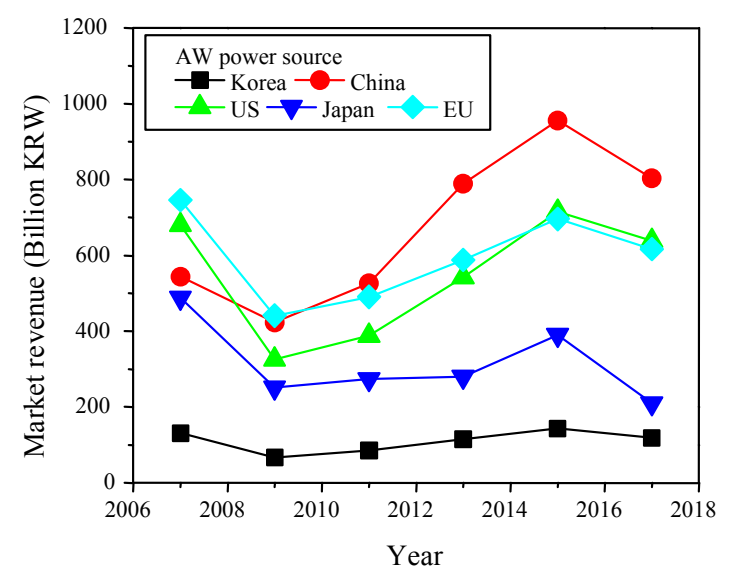

(b)

Fig. 3 Trends for arc welding power source market according to countries: (a) unit sales and (b) market revenue

Table 1 Unit price of arc welding power source (unit: Million KRW)

\begin{tabular}{|c|c|c|c|c|}
\hline Korea & China & US & Japan & EU \\
\hline 2.12 & 1.40 & 4.16 & 4.12 & 3.74 \\
\hline
\end{tabular}

Fig. 4 shows the status of the resistance welding power source market by country. The Chinese market has continuously grown, with the market size in 2017 twice that of 2007. Resistance welding power sources are primarily used for thin plate welding and the main application industry is the automotive industry. This market growth can be attributed to the automotive industry's growth in China. Whereas the average unit price of resistance welding power sources in other major countries is 15 thousand dollars, it is considerably low in China with 6.6 thousand dollars. This is likely because SCR welding power sources, which are cheaper than inverter power sources are being primarily used in China. The number of units and sales of the Korean and 


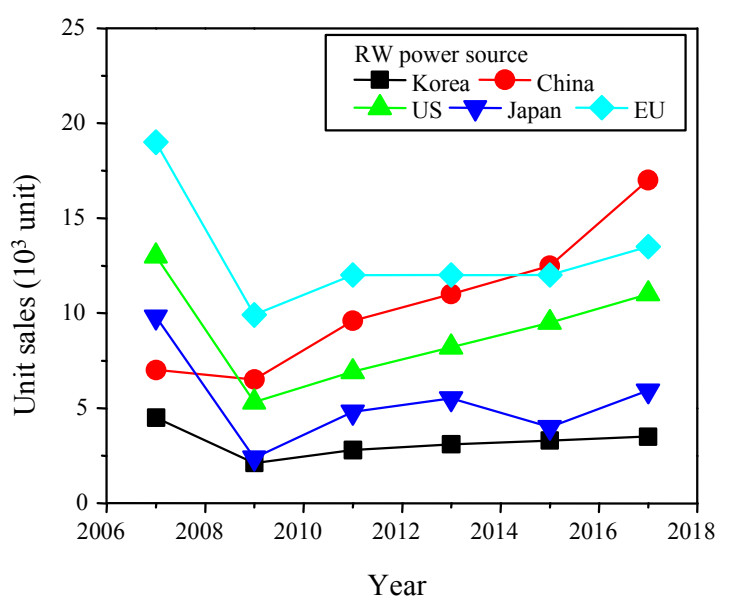

(a)

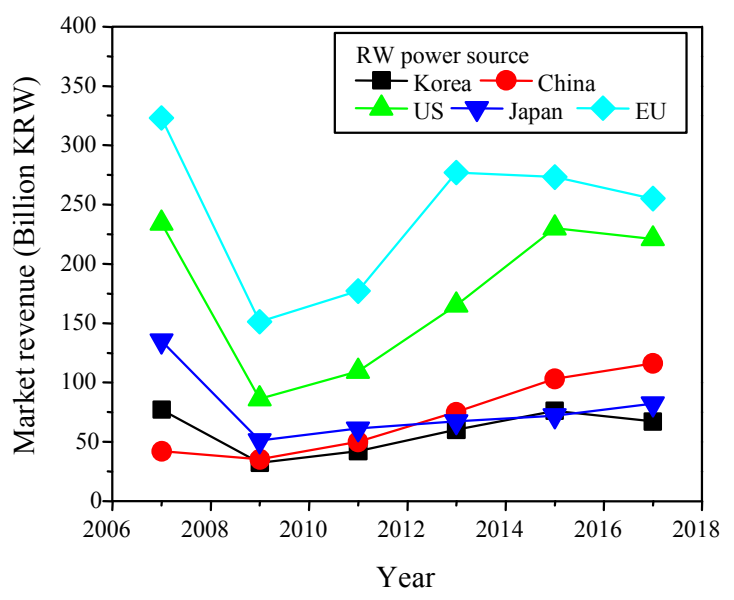

(b)

Fig. 4 Trends for resistance welding power source market according to countries: (a) unit sales and (b) market revenue

North American resistance welding power source markets in 2017 were just slightly lower than those in 2007, though the Japanese and EU markets recovered only $60 \%$ and $80 \%$ compared to 2007 sales.

\section{Status of the Global Welding Robot Market}

Since hitting a low in the 2008 economic crisis, the global welding robot market has been continuously growing (Figs. $5 \& 6$ ). However, compared to the similar sizes of the global welding power source markets in 2007 and 2017 (Figs. 1 \& 2), the welding robot market nearly doubled in size from 2007 to 2017 . This is because the use of welding robots is highly related to the automation rate. That is, though the sizes of welding application industries in 2017 were similar to that in 2007, their automation rates substantially increased. As of 2017, the global arc welding robot market recorded sales of 33,000 units and 1.3 million

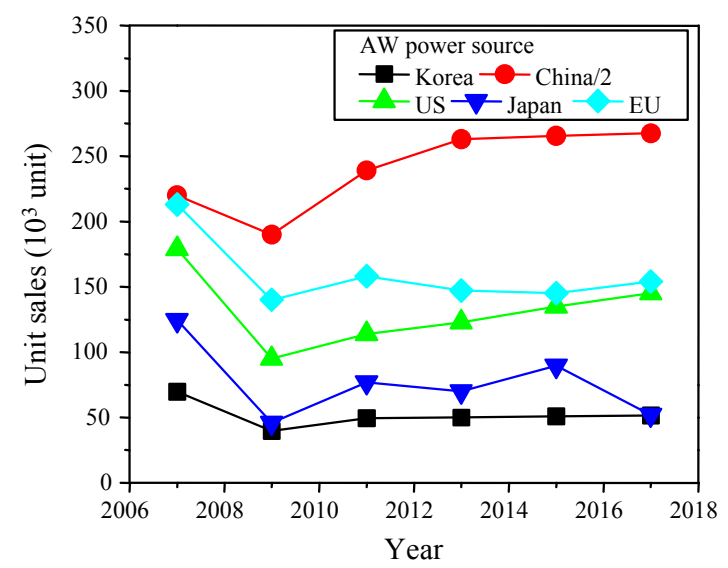

Fig. 5 Global market trends for arc welding robot

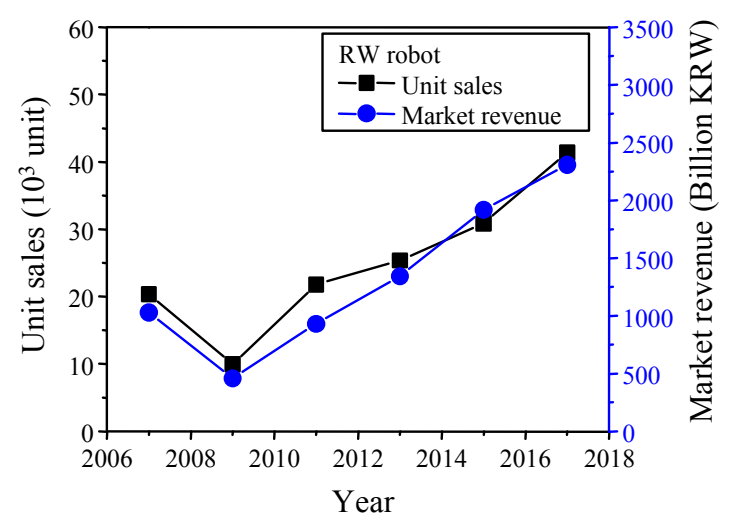

Fig. 6 Global market trends for resistance welding robot

dollars, while the resistance welding robot market recorded sales of 41,000 units and 1.9 million dollars. Given that 1.38 million and 70,000 units of arc welding and resistance welding power sources were sold in $2017,58.6 \%$ of resistance welding power source sales were for welding robots, whereas only $2.4 \%$ of arc welding power source sales were for welding robots.

Fig. 7 shows the arc welding robot market status by country. The Chinese market, which is the largest, shows unparalleled growth compared to the other major countries. In 2017, the Korean arc welding robot market recorded sales of 3,000 units and 85 million dollars. As arc welding robots are primarily imported from Japan, this was selected as one of the top 100 strategic items related to the Japanese export regulations to Korea in 2019. Japan is the only major country that has yet to recover 2007-level sales and revenue, indicating that the country has yet to recover its previous levels of competitiveness in heavy industry.

Fig. 8 shows the resistance welding robot market status by country. China recorded a similar resistance welding robot market size to the United States and is expected to overtake the United States in the near 


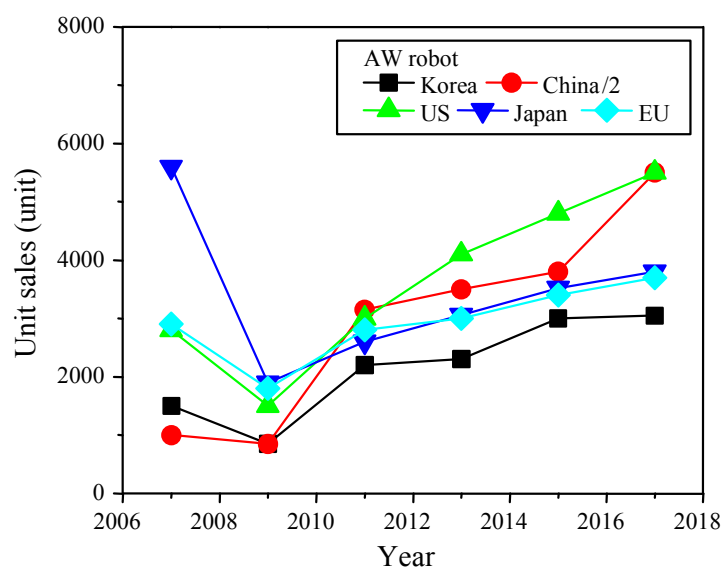

(a)

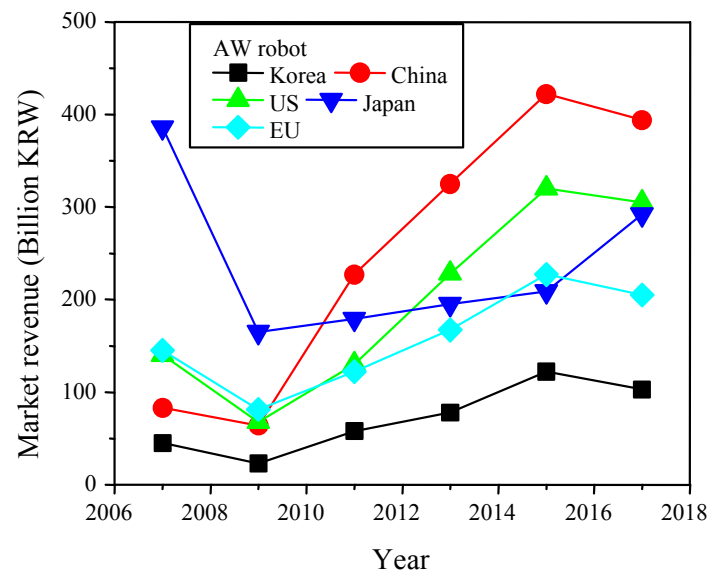

(b)

Fig. 7 Trends for arc welding robot market according to countries: (a) unit sales and (b) market revenue

future. In 2017, the Korean resistance welding robot market recorded sales of 2,000 units and 70 million dollars, showing a slight improvement over 2007 and a relatively low growth rate compared to other major countries. To overcome this, it is necessary to enhance the global competitiveness of the Korean automotive industry, a major application industry, and increase investments in production.

\section{Implications}

This article summarized data on the global and countryspecific markets for the arc and resistance welding power source as well as the robots. As the primary application industries of arc and resistance welding are the heavy industry and the automotive industry, respectively, the status of the welding power source and robot markets are much related to the status of the application industries. Accordingly, to promote the welding power source and robot industries, it is necessary to enhance the sales and competitiveness of heavy industry and the automotive industry.

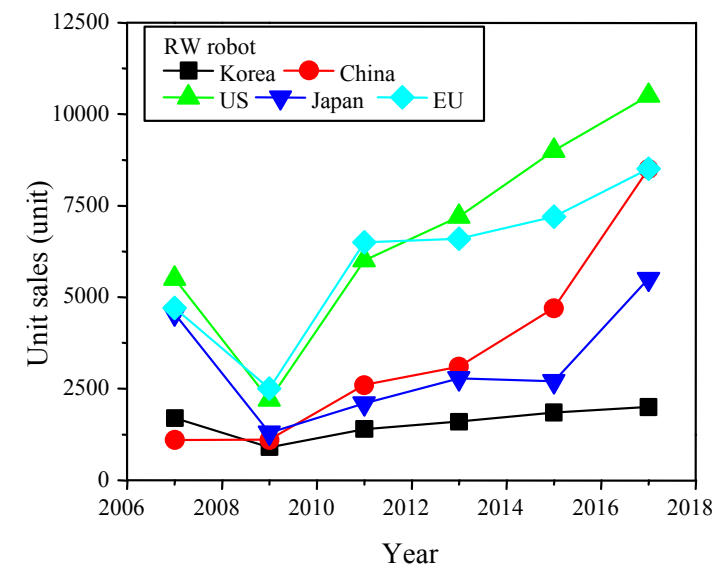

(a)

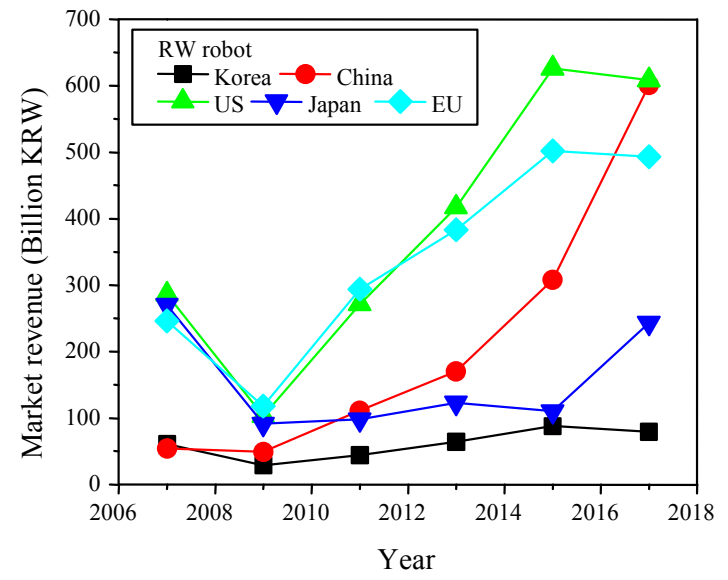

(b)

Fig. 8 Trends for resistance welding robot market according to countries: (a) unit sales and (b) market revenue

Even though welding robots and welding power sources have a common and essential platform to implement automated welding, the market share of imported arc welding robots and power sources is extraordinarily high unlike resistance welding robots. In the future, welding automation and application of artificial intelligence in welding processes are expected to increase. As production platforms are prerequisite for implementing these technology, it is necessary to localize welding robots and power sources. This will become the foundation for the global competitivenss of the Korean automotive industry and heavy industry.

ORCID: Seungjae Lee: http://orcid.org/0000-0003-0413-8587

ORCID: Jason Cheon: http://orcid.org/0000-0003-2271-2511

ORCID: Cheolhee Kim: http://orcid.org/0000-0003-4127-3171

\section{References}

1. J. Y. Han, C. Kim, J. K. Kim, N. H. Kang and J. H. 
Kim, Statistical Analysis of Korean Welding Industry, J. Korean Weld. Soc. 23(5) (2005) 222-227.

2. C. Kim, M. J. Kang and S. Bae, Statistical Analysis of Korean Welding Industry (II), J. Korean Weld. Join. Soc. 26(6) (2008) 552-555.

3. D. Moon, M. J. Kang and C. Kim, Statistical Analysis of Korean Welding Industry (III), J. Korean Weld. Join. Soc. 30(5) (2012) 403-406.

https://doi.org/10.5781/KWJS.2012.30.5.403

4. S. Lee and C. Kim, Statistical Analysis of Korean Welding Industry (IV), J. Weld. Join. 37(2) (2019), 66-69.

https://doi.org/10.5781/JWJ.2019.37.2.10
5. C. Kim, D. Moon and S. Moon, Statistical Analysis of World Welding Consumables Market, J. Korean Weld. Join. Soc. 30(5) (2012) 403-406.

http://dx.doi.org/10.5781/KWJS.2012.30.5.398

6. S. Lee and C. Kim, Statistical Analysis of World Welding Consumables Market (II), J. Weld. Join. 37(4) (2019) 318-321. https://doi.org/10.5781/JWJ.2019.37.4.5

7. Korean Welding and Joining Society, Welding and Joining Handbook, III: Welding and Related Processes, Korean Welding and Joining Society, Daejeon, Korea (2007) 294.

8. Welding Market Annual Research \& Trend, Shimpo, Osaka, Japan (2007 2017). 